\title{
Deregulated expression of Nucleophosmin 1 in gastric cancer and its clinicopathological implications
}

Mariana Ferreira Leal ${ }^{1,2^{*}}$, Tatiane Katsue Furuya Mazzotti ${ }^{3,4}$, Danielle Queiroz Calcagno ${ }^{1,5}$, Priscila Daniele Ramos Cirilo ${ }^{3,4}$, Margarita Cortes Martinez ${ }^{3,4}$, Samia Demachki ${ }^{5}$, Paulo Pimentel Assumpção ${ }^{5}$, Roger Chammas ${ }^{3,4}$, Rommel Rodríguez Burbano ${ }^{6}$ and Marília Cardoso Smith ${ }^{1}$

\begin{abstract}
Background: The process of gastric carcinogenesis still remains to be elucidated. The identification of genes related to this process may help to reduce mortality rates through early diagnosis and the development of new anticancer therapies. Nucleophosmin 1 (NPM1) acts in ribosome biogenesis, centrosome duplication, maintenance of genomic stability, and embryonic development. Recently, NPM1 has been implicated in the tumorigenesis processes. Here, we evaluated NPM1 gene and protein expression in gastric tumors and in corresponding non-neoplastic gastric samples.

Methods: NPM1 protein expression was determined by Western blot in 17 pairs of gastric tumors and corresponding non-neoplastic gastric tissue. The protein immunoreactivity was observed in 12 tumor samples. mRNA expression was evaluated by reverse transcription quantitative polymerase chain reaction (RT-qPCR) in 22 pairs of gastric tumors and in matched non-neoplastic gastric tissue.

Results: NPM1 protein expression was significantly reduced in gastric cancer samples compared to matched non-neoplastic gastric samples $(P=0.019)$. The protein level of NPM1 was reduced at least 1.5 -fold in $35 \%$ of tumors compared to paired non-neoplastic gastric tissue. However, NPM1 immunoreactivity was detected in neoplastic and non-neoplastic cells, including in intestinal metaplastic, gastritis and inflammatory cells. NPM1 was mainly expressed in nucleus and nucleolus subcellular compartments. The staining intensity and the percentage of immunoreactive cells varied among the studied cases. The NPM1 mRNA level was reduced at least 1.5 -fold in $45.5 \%$ of samples and increased in $27.3 \%$ of samples. An inverse correlation between protein and mRNA expression was detected ( $r=-0.509, P=0.037)$. Intestinal-type gastric cancer presented higher mRNA levels than diffuse-type $(P=0.026)$. However, reduced NPM1 protein expression was associated with intestinal-type gastric cancer compared to matched non-neoplastic gastric samples $(P=0.018)$. In addition, tumors from patients with known distant metastasis presented reduced NPM1 protein levels compared to tumors from patients without distant metastasis $(P<0.001)$.
\end{abstract}

Conclusion: Although the expression of NPM1 is heterogeneous in gastric tumors, our results suggest that NPM1 down-regulation may have a role in gastric carcinogenesis and may help in the selection of anticancer treatment strategies.

Keywords: Gastric cancer, Nucleophosmin, Gene expression, Protein expression

\footnotetext{
* Correspondence: mariana.morf@epm.br

${ }^{1}$ Genetics Division, Department of Morphology and Genetic, Federal

University of São Paulo, R. Botucatu, 740, São Paulo, SP CEP 04023-900, Brazil

${ }^{2}$ Department of Orthopedics and Traumatology, Federal University of São

Paulo, São Paulo, SP 04038-031, Brazil

Full list of author information is available at the end of the article
}

\section{Biomed Central}

(C) 2014 Leal et al.; licensee BioMed Central Ltd. This is an open access article distributed under the terms of the Creative Commons Attribution License (http://creativecommons.org/licenses/by/2.0), which permits unrestricted use, distribution, and reproduction in any medium, provided the original work is properly cited. 


\section{Background}

Gastric cancer (GC) is the fourth most common cancer and the second leading cause of cancer-related death worldwide [1]. Although this neoplasia is a serious public health problem due to its high incidence and mortality, little is known about the molecular events involved in gastric carcinogenesis.

Our group recently performed a proteomic analysis aiming to identify proteins with a role in gastric carcinogenesis [2]. In this study, we observed reduced expression of nucleophosmin 1 (NPM1, also known as $\mathrm{B} 23$, numatrin and NO38) in several gastric tumors compared to non-neoplastic gastric samples by twodimensional electrophoresis and mass spectrometry. NPM1 is a nucleolar phosphoprotein that shuttles continuously between the nucleus and the cytoplasm (see review [3]). NPM1 function is not completely known. NPM1 is a member of the nucleoplasmin family of histone chaperones that favor DNA-histone and nucleosome assembly in vitro and also interact with a wide range of unfolded proteins, inducing proper folding in the active state [4]. These multifunctional proteins act in ribosome biogenesis [5], centrosome duplication [6,7], maintenance of genomic stability, and embryonic development [8].

Not surprisingly, NPM1 has been implicated in tumorigenesis processes. NPM1 overexpression was described in solid tumors of diverse histological origins, including astrocytomas [9], as well as colon [10], hepatocellular [11], bladder [12], breast [13], ovarian [14] and prostate [15] carcinomas. Deletions and chromosomal translocations involving the NPM1 locus (5q35) were described in hematological malignancies (see reviews [16,17]) and lung cancer [18]. Mutations of NPM1 were also described in hematological malignancies, and it has been suggested that NPM1-mutated acute myeloid leukemia is a distinct leukemia entity [19].

NPM1 seems to play a role as both a tumor suppressor and an oncogene. For its tumor suppressor activity, NPM1 seems to act directly and indirectly on the regulation of p53 [3]. On the other hand, NPM1 is also involved in transcriptional activation of some oncogenes, such as MYC [20]. Therefore, NPM1 overexpression leads to increased cell growth and proliferation and inhibits differentiation and apoptosis [3].

To our knowledge, only two studies have evaluated NPM1 mRNA expression in a small set of human primary GC [21,22]. Thus, the role of NPM1 in gastric carcinogenesis remains to be elucidated. In the present study, we analyzed NPM1 mRNA and protein expression in GC and matched non-neoplastic gastric samples. We also evaluated the possible associations between NPM1 and clinicopathological characteristics.

\section{Methods}

\section{Tissue samples}

NPM1 mRNA expression was evaluated in 22 pairs of GC samples and matched non-neoplastic gastric tissue ( $>5 \mathrm{~cm}$ from the edge of the tumor). In 17 pairs of these GC samples and corresponding non-neoplastic gastric tissue, the protein expression was also evaluated. The protein immunoreactivity was assessed in 12 tumors.

All the gastric samples were obtained from patients who underwent gastrectomy for GC at João de Barros Barreto University Hospital (HUJBB) in the State of Pará, Northern Brazil, during the period from 2006 to 2010. Informed consent with approval of the ethics committee of HUJBB was obtained. All patients had negative histories of exposure to either chemotherapy or radiotherapy before surgery, and there was no co-occurrence of other diagnosed cancers.

Part of the dissected tumor samples was formalinfixed and paraffin embedded (FFPE). Sections of FFPE tissue were stained with hematoxylin-eosin for histological evaluation or used for immunohistochemistry analysis (IHC). The other part of tumors and the paired non-neoplastic tissue specimens were immediately cut from resected stomachs, frozen in liquid nitrogen and kept at $-80^{\circ} \mathrm{C}$ until protein and nucleic acid extraction.

Table 1 shows the clinicopathological characteristics of the GC samples. All samples were classified according to Laurén [23], and tumors were staged using standard criteria by TNM staging [24]. The presence of $H$. pylori, a class I carcinogen, in GC and non-neoplastic samples was detected by PCR assay. PCR for the urease gene [25] and for the $H$. pylori virulence factor cytotoxinassociated gene A (CagA) [26] was performed as previously reported using the DNA purified simultaneously with the proteins and the mRNA. All reactions were performed in duplicate. In each PCR experiment, positive and negative controls were included. A sample was considered positive if a clear and visible band was observed on the electrophoresis gel ( $2 \%$ agarose gel). In our sample, all GC and non-neoplastic samples presented $H$. pylori infection.

\section{Protein and mRNA purification}

Total protein and mRNA were simultaneously isolated from the gastric tissue samples using the AllPrep DNA/ RNA/Protein Kit (Qiagen, Germany) according to the manufacturer's instructions. The protein pellet was dissolved in a buffer containing $7 \mathrm{M}$ urea, $2 \mathrm{M}$ thiourea, $4 \%$ 3-[(3-cholamidopropyl) dimethylammonio]-1-propanesulfonate (CHAPS), $50 \mathrm{mM}$ dithiothreitol (DTT), 1\% Protease Inhibitor Cocktail (Sigma) and 0.5\% each of Phosphatase Inhibitor Cocktails 1 and 2 (Sigma-Aldrich, USA). The protein concentration was determined by the Bradford method (Sigma-Aldrich, USA). The RNA 
Table 1 Clinicopathological characteristics NPM1 expression in gastric cancer samples

\begin{tabular}{|c|c|c|c|c|c|c|}
\hline \multirow[b]{2}{*}{ Variable } & \multicolumn{3}{|c|}{ NPM1 protein } & \multicolumn{3}{|c|}{ NPM1 mRNA } \\
\hline & $\mathrm{N}$ & Ratio T/N (Mean \pm SD) & $P$ value & $\mathrm{N}$ & RQ (Mean \pm SD) & $P$ value \\
\hline \multicolumn{7}{|l|}{ Gender } \\
\hline Male & 8 & $0.81 \pm 0.36$ & 0.431 & 12 & $2.47 \pm 3.86$ & 0.657 \\
\hline Female & 9 & $0.67 \pm 0.39$ & & 10 & $1.76 \pm 3.43$ & \\
\hline \multicolumn{7}{|l|}{ Onset (years) } \\
\hline$<45$ & 5 & $0.73 \pm 0.48$ & 0.973 & 7 & $0.95 \pm 0.89$ & 0.298 \\
\hline$\geq 45$ & 12 & $0.74 \pm 0.34$ & & 15 & $2.70 \pm 4.25$ & \\
\hline \multicolumn{7}{|l|}{ Tumor location } \\
\hline Cardia & 2 & $0.87 \pm 0.04$ & 0.601 & 2 & $0.17 \pm 0.19$ & 0.429 \\
\hline Non-cardia & 15 & $0.72 \pm 0.39$ & & 20 & $2.34 \pm 3.73$ & \\
\hline \multicolumn{7}{|l|}{ Histological subtype } \\
\hline Diffuse-type & 4 & $0.97 \pm 0.25$ & 0.159 & 6 & $0.33 \pm 0.28$ & $0.026^{*}$ \\
\hline Intestinal-type & 13 & $0.66 \pm 0.38$ & & 16 & $2.83 \pm 4.04$ & \\
\hline \multicolumn{7}{|l|}{ Differentiation } \\
\hline Moderately differentiated & 8 & $0.72 \pm 0.38$ & 0.492 & 10 & $2.84 \pm 4.14$ & 0.990 \\
\hline Poorly differentiated & 5 & $0.57 \pm 0.40$ & & 6 & $2.81 \pm 4.26$ & \\
\hline \multicolumn{7}{|l|}{ Stage } \\
\hline Early & 4 & $0.66 \pm 0.31$ & 0.675 & 4 & $1.02 \pm 1.05$ & 0.472 \\
\hline Advanced & 13 & $0.76 \pm 0.40$ & & 17 & $2.54 \pm 4.01$ & \\
\hline \multicolumn{7}{|l|}{ Tumor invasion } \\
\hline $\mathrm{T} 1 / \mathrm{T} 2$ & 7 & $0.78 \pm 0.27$ & 0.672 & 9 & $1.61 \pm 1.63$ & 0.502 \\
\hline $\mathrm{T} 3 / \mathrm{T} 4$ & 10 & $0.70 \pm 0.44$ & & 12 & $2.73 \pm 4.67$ & \\
\hline \multicolumn{7}{|l|}{ Lymph node metastasis } \\
\hline Absent & 6 & $0.78 \pm 0.30$ & 0.757 & 7 & $1.48 \pm 1.82$ & 0.509 \\
\hline Present & 11 & $0.71 \pm 0.42$ & & 14 & $2.63 \pm 4.31$ & \\
\hline \multicolumn{7}{|l|}{ Distant metastasis } \\
\hline Unknown/absent & 14 & $0.86 \pm 0.26$ & $<0.001^{a}$ & 18 & $1.21 \pm 1.29$ & 0.220 \\
\hline Present & 3 & $0.15 \pm 0.20$ & & 3 & $8.49 \pm 7.18$ & \\
\hline
\end{tabular}

T, tumor sample; $\mathrm{N}$, matched non-neoplastic sample; SD, standard deviation; RQ, relative quantification - gastric tumor samples normalized by matched nonneoplastic sample. "Differentially expressed between groups, $P<0.05$, using t-test for independent samples.

concentration and quality were determined using a NanoDrop spectrophotometer (Kisker, Germany), and the RNA integrity was determined by gel electrophoresis.

\section{NPM1 protein expression by Western blot}

Reduced protein $(20 \mu \mathrm{g})$ from each sample was separated on a $12.5 \%$ homogeneous SDS-PAGE gel and electro-blotted to a polyvinylidene difluoride (PVDF) membrane (Hybond-P, GE Healthcare, USA). The PVDF membrane was blocked with phosphate-buffered saline containing $0.1 \%$ Tween 20 and 5\% low fat milk and incubated overnight at $4^{\circ} \mathrm{C}$ with anti-NPM1 (FC-61991, 1:500, Invitrogen, USA) and anti- $\beta$-Actin antibodies (ACTB; Ac-74, 1:3000, Sigma-Aldrich, USA). After extensive washing, the PVDF membrane was incubated with a peroxidaseconjugated secondary antibody for 1 hour at room temperature. Immunoreactive bands were visualized using Western blotting Luminol reagent, and the images were acquired using an ImageQuant 350 digital image system (GE Healthcare, Sweden). ImageJ 1.43u software (National Institutes of Health, USA) was used for gel band quantitative densitometric analysis. ACTB was used as a loading reference control. In each experiment, tumor and matched non-neoplastic samples were applied to the same gel. One of the non-neoplastic samples (reference) was applied to all gels to allow comparison among different experiments.

\section{NPM1 immunoreactivity by IHC}

Paraffin sections from 12 different tumor samples were subjected to IHC. Tumor tissue sections (3 or $4 \mathrm{~mm}$ thick) were deparaffinized in xylene and rehydrated in a graded series of ethanol. After heat-induced epitope retrieval, the tissue sections were incubated with primary 
mouse monoclonal antibody against NPM1 (NA24, 1:200, Neomarkes, USA). A universal peroxidase-conjugated secondary antibody kit (LSAB System, DakoCytomation, USA) was used for the detection system. We used 3.30diamino-benzidine $/ \mathrm{H}_{2} \mathrm{O}_{2}$ (Dakocytomation, Denmark) as the chromogen and hematoxylin as the counterstain. Negative controls in which the primary antibody was replaced by bovine serum albumin (BSA) $5 \%$ in phosphatebuffered saline (PBS) were performed in all series, and sections of normal human amygdala tissue were used as positive controls.

The slides were viewed by light microscopy using a Nikon Eclipse E600 microscope (Nikon, NY, USA) equipped with a digital camera Nikon DSM1200F (Nikon, NY, USA). The nonstained region (white region) was selected and set as background. Any staining was considered to be a positive result, irrespective of intensity. An arbitrary semiquantitative score was developed to quantify NPM1 immunoreactivity, as follows: 0 , from negative to minimal staining ( $<10 \%$ of cells); $1+$, for those tumors showing a weak staining and over $10 \%$ of cells; $2+$, for those tumors presenting a moderate staining and over $10 \%$ of cells; and $3+$, for those tumors presenting a strong staining and over $10 \%$ of cells.

\section{NPM1 mRNA expression by reverse transcription quantitative polymerase chain reaction (qRT-PCR)}

First, complementary DNA was synthesized using the High-Capacity cDNA Archive kit (Applied Biosystems, Poland) according to the manufacturer's protocol. All real-time RT-qPCR reactions were performed in triplicate for both the target gene (NPM1: Hs01576587_g1, Applied Biosystems, USA) and the internal control (ACTB: Hs03023943_g1, Applied Biosystems, USA). The relative quantification ( $R Q$ ) of the gene expression was calculated according to Pfaffl method [27]. A nonneoplastic gastric tissue was designed as a calibrator for all samples for the comparison between neoplastic and non-neoplastic samples. In addition, the non-neoplastic gastric tissue sample was designated as a calibrator for each paired tumor for clinicopathological analysis.

\section{Statistical analysis}

Gene and protein expression data are shown as mean \pm standard deviation (SD) for each group. We first evaluated the normal distribution of all data using the Shapiro-Wilk normality test to determine the subsequent use of appropriate tests for statistical comparison. NPM1 mRNA levels were not normally distributed and were transformed ( $\mathrm{z}$-score) for analysis such that they followed a normal distribution. Paired t-tests were performed to compare the mean NPM1 expression between non-neoplastic and tumor samples. The associations between the clinicopathological parameters and the mean
NPM1 mRNA and protein expression were assessed using t-tests for independent samples. The possible associations between NPM1 immunoreactivity and clinicopathological parameters were assessed by Fisher's exact test. The correlation between NPM1 immunoreactivity and mRNA or protein expression by Western blot was analyzed by Spearman's rank correlation test. The correlation between NPM1 mRNA and protein expression by Western blot was analyzed by Pearson's test. For the analyses using the t-test for independent samples and the Pearson's test, the NPM1 expression in tumor samples was calibrated by their matched non-neoplastic counterpart. In all analyses, $P<0.05$ was considered significant.

\section{Results}

NPM1 protein expression was significantly reduced in GC samples compared to matched non-neoplastic gastric samples $(0.99 \pm 0.54$ vs $1.39 \pm 0.39$, values relative to the reference sample; $P=0.019$, by paired t-test; Figure $1 \mathrm{~A}$ ). The protein level of NPM1 was reduced at least 1.5-fold (50\% decrease in the expression) in $35 \%$ of GC samples, and no tumor presented an increase in expression of 50\% compared to their paired non-neoplastic gastric tissue (Figure $1 \mathrm{~B}$ and $1 \mathrm{C}$ ).

In all cases, the NPM1 immunoreactivity was detected in neoplastic and non-neoplastic cells, including in intestinal metaplastic, gastritis and inflammatory cells (Figure 2A-H). NPM1 was mainly expressed in nucleus and nucleolus. Only one case presented cytoplasmatic staining in the parietal cells (Figure 2B). The staining intensity and the percentage of immunoreactive cells varied among the studied cases (Table 2). In nuclei of tumor cells, NPM1 immunoreactivity score ranged from 0 to 2 , with $41.7 \%$ cases presenting score 0 . In nucleoli of tumor cells, 5 of 12 cases (41.7\%) presented score 0 and 7 of 12 (58.3\%) presented score 2. The score of NPM1 immunoreactivity in the nucleoli of tumor cells was inversely correlated with the protein expression by Western blot $(\mathrm{r}=-0.693, \mathrm{p}=0.039$; by Spearman's correlation $)$.

The NPM1 mRNA expression did not differ between GC and matched non-neoplastic gastric samples $(0.29 \pm$ 0.41 vs $0.39 \pm 0.42$, values relative to a calibrator nonneoplastic sample; $P=0.33$, by paired t-test; Figure $1 D$ ). The NPM1 mRNA level was reduced at least 1.5-fold in $45.5 \%$ of samples and increased in $27.3 \%$ of samples (Figure 1E). A moderate inverse correlation was observed between the relative quantifications of NPM1 protein and mRNA levels $(\mathrm{r}=-0.509 ; P=0.037$, by Pearson's correlation; Figure 1F).

The intestinal-type GC presented higher NPM1 mRNA levels than diffuse-type GC ( $P=0.026$, by t-test; Table 1$)$. The mRNA expression was at least $50 \%$ reduced in all diffuse-type. In the intestinal-type, the mRNA expression 


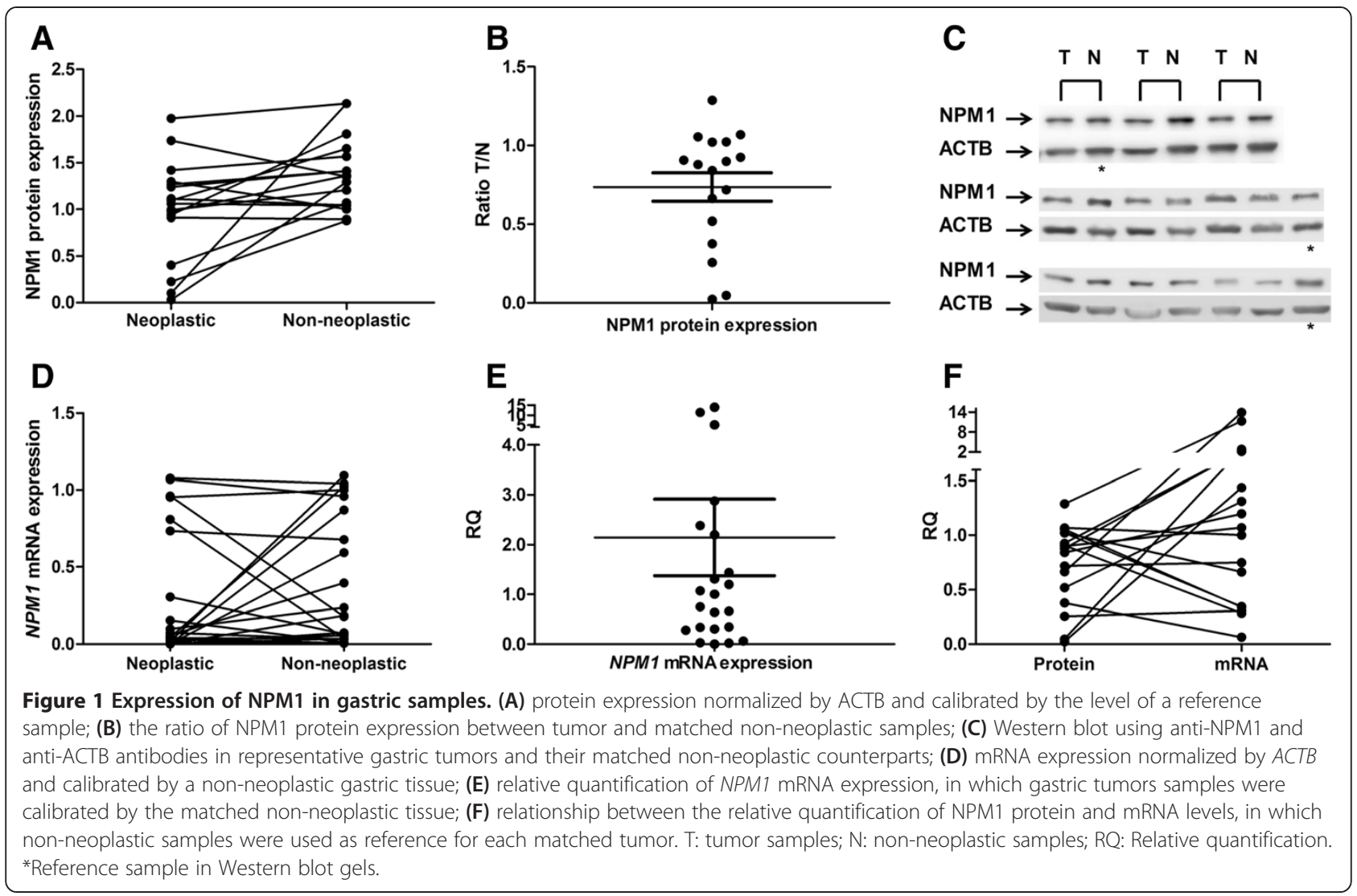

was less than 1.5 -fold in $25 \%$ of cases and greater than 1.5 -fold in $37.5 \%$ in relation to their matched non-neoplastic counterpart. On the other hand, the NPM1 protein level did not differ between diffuse-type and intestinal-type GC. However, intestinal-type GC presented a significant reduction of NPM1 protein expression compared to matched non-neoplastic gastric samples $(0.94 \pm 0.58$ vs $1.41 \pm 0.42$, $P=0.018$, by paired t-test). In addition, the protein level of NPM1 was reduced at least 1.5 -fold in $46.2 \%$ of intestinaltype GC and in no case of diffuse-type GC.

Tumors from patients with known distant metastasis showed reduced NPM1 protein expression compared to tumors from patients without distant metastasis $(P<$ 0.001 , by t-test; Table 1$)$. No association between NPM1 expression and any other clinicopathological characteristics was found.

\section{Discussion}

NPM1 is a multifunctional protein. The first proposed role of NPM1 was in the regulation of cell growth, proliferation and transformation because its expression increases in response to mitogenic stimuli and is up-regulated in highly proliferative and malignant cells. However, several recent studies have demonstrated that NPM1 has both proliferative and growth-suppressive roles in the cell (see review [3]).
In the present study, NPM1 protein expression was significantly down-regulated in GC, which supports its role as a tumor suppressor. One NPM1 target is cyclindependent kinase inhibitor 2A (CDKNA2) alternate reading frame protein (ARF; also known as p14ARF in humans, and p19Arf in the mouse). ARF protein is involved in cell-cycle arrest and apoptotic processes through inhibition of MDM2 (E3 ubiquitin-protein ligase, a negative regulator of p53) and, therefore, stabilization of p53 [28]. NPM1 acts in the stabilization of ARF within the nucleolus by protecting it from both proteasome-dependent and proteasome-independent degradation. It has been suggested that NPM1 loss of function could lead to an acceleration of tumorigenesis owing to the destabilization and inactivation of ARF, which is known to inhibit cell proliferation through both p53-dependent and p53independent mechanisms [3,29], in agreement with a potential tumor-suppressor role for NPM1.

The down-regulation of NPM1 was associated with known distant metastasis in patients with GC, suggesting that low levels of NPM1 protein expression may be a marker of poor prognosis in GC if validated in larger clinical study sets. Reduced NPM1 protein level was previously associated with poor outcome in some subtypes of breast cancer [30]. On the other hand, NPM1 overexpression was associated with the presence of distant 

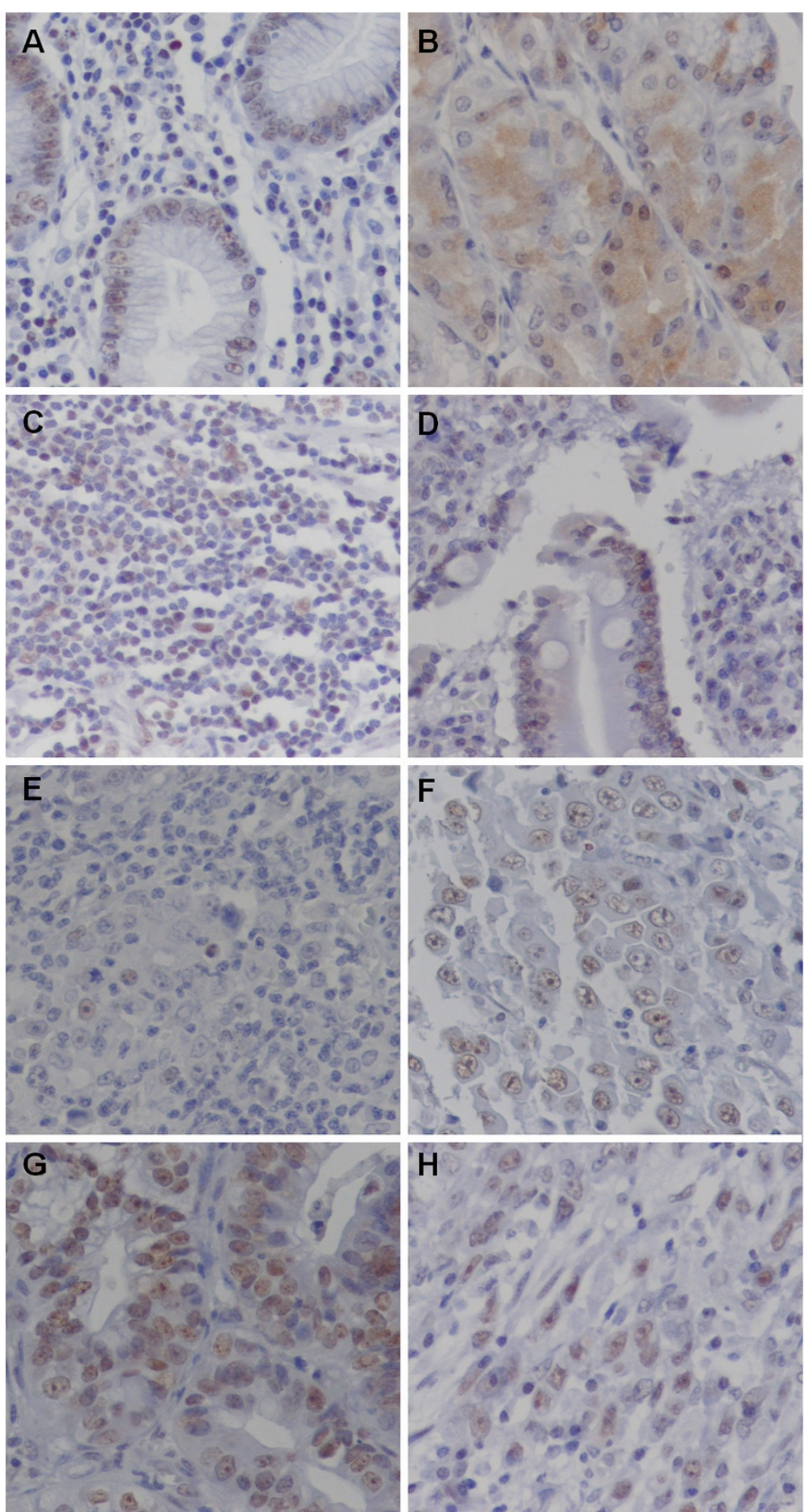

Figure 2 Immunohistochemical analysis of NPM1 in gastric samples. (A) NPM1 staining in normal gastric mucosa (400X); (B) cytoplasmatic NPM1 staining in parietal cells (400X); (C) NPM1 immunoreactivity in inflammatory cells (400X); (D) NPM1 staining in intestinal metaplastic cells (400X); (E) minimal NPM1 staining in a poorly differentiated tumor (400X); (F) weak NPM1 staining in a poorly differentiated tumor (400X); (G) moderate NPM1 staining in a moderately differentiated tumor (400X); $(\mathbf{H})$ moderate NPM1 staining in a diffuse-type tumor (400X). 
Table 2 Immunohistochemistry analysis in gastric tumors

\begin{tabular}{|c|c|c|c|c|c|c|c|}
\hline Case & Histological subtype & Differentiation & Stage & $\%$ of stained tumor cells & Location & Intensity of staining & Score \\
\hline \multirow[t]{2}{*}{1} & Intestinal-type & Moderately differentiated & 1 & $60 \%$ & Nucleus & Moderate & 2 \\
\hline & & & & & Nucleolus & Moderate & 2 \\
\hline \multirow[t]{2}{*}{2} & Intestinal-type & Poorly differentiated & 4 & $<10 \%$ & Nucleus & Weak & 0 \\
\hline & & & & & Nucleolus & Moderate & 0 \\
\hline \multirow[t]{2}{*}{3} & Intestinal-type & Moderately differentiated & 4 & $40 \%$ & Nucleus & Weak & 1 \\
\hline & & & & & Nucleolus & Moderate & 2 \\
\hline \multirow[t]{2}{*}{4} & Intestinal-type & Moderately differentiated & 1 & $20 \%$ & Nucleus & Moderate & 2 \\
\hline & & & & & Nucleolus & Moderate & 2 \\
\hline \multirow[t]{2}{*}{$5^{*}$} & Intestinal-type & Moderately differentiated & 1 & $40 \%$ & Nucleus & Weak & 1 \\
\hline & & & & & Nucleolus & Moderate & 2 \\
\hline \multirow[t]{2}{*}{6} & Intestinal-type & Poorly differentiated & 3 & $<10 \%$ & Nucleus & Weak & 0 \\
\hline & & & & & Nucleolus & Weak & 0 \\
\hline \multirow[t]{2}{*}{7} & Intestinal-type & Moderately differentiated & 1 & $<10 \%$ & Nucleus & Weak & 0 \\
\hline & & & & & Nucleolus & Weak & 0 \\
\hline \multirow[t]{2}{*}{8} & Intestinal-type & Moderately differentiated & 3 & $<10 \%$ & Nucleus & Weak & 0 \\
\hline & & & & & Nucleolus & Weak & 0 \\
\hline \multirow[t]{2}{*}{9} & Intestinal-type & Moderately differentiated & 4 & $20 \%$ & Nucleus & Weak & 1 \\
\hline & & & & & Nucleolus & Moderate & 2 \\
\hline \multirow[t]{2}{*}{10} & Intestinal-type & Moderately differentiated & 2 & $<10 \%$ & Nucleus & Weak & 0 \\
\hline & & & & & Nucleolus & Weak & 0 \\
\hline \multirow[t]{2}{*}{11} & Intestinal-type & Poorly differentiated & 3 & $40 \%$ & Nucleus & Weak & 1 \\
\hline & & & & & Nucleolus & Moderate & 2 \\
\hline \multirow[t]{2}{*}{12} & Diffuse-type & Not applied & 3 & $20 \%$ & Nucleus & Moderate & 2 \\
\hline & & & & & Nucleolus & Moderate & 2 \\
\hline
\end{tabular}

*This patient presented strong cytoplasmatic immunoreactivity in normal parietal cells (score $=3$ ).

metastasis in colon cancer [31]. The role of NPM1 may depend on cellular and genetic context. The interaction between NPM1 and MYC may be one of the pathways by which the loss of NPM1 contributes to the development of metastasis. The lack of a functional NPM1 was previously associated with increased levels of MYC [32]. $M Y C$ is a key oncogene in gastric carcinogenesis (see review [33]), and the overexpression or amplification of the $M Y C$ locus was previously reported in GC samples and preneoplastic gastric lesions [34-41]. In our population, MYC overexpression was previously associated with the presence of distant metastasis [42]. Moreover, the three tumors of patients with distant metastasis presented MYC immunoreactivity (data not shown).

Here, we observed that NPM1 presented nuclear and nucleolar location. Previous studies showed that NPM1 is a predominantly nucleolar protein, however, a fraction can also be detected in the nucleoplasm (see review [43]). Although the sample size is small, an inverse correlation between nucleoli immunoreactivity and the protein expression (total expression) by Western blot was observed. This finding may be in part to the key role of
NPM1 in ribosome biogenesis. In both subcellular compartments, the NPM1 immunoreactivity presented a large inter- and intra-tumor heterogeneity. The NPM1 expression heterogeneity in GC cells may complicate the development of diagnostic tests or treatments targeting the NPM1. Efforts to pharmacologically target NPM1 for cancer therapy might be difficult, due to the fact that its function is likely to be tightly regulated to avoid the possibly detrimental consequences of its decreased or increased function [3].

The NPM1 immunoreactivity was also heterogeneous in intestinal metaplastic, gastritis and inflammatory cells, which are commonly observed in GC patients. NPM1 may also act as an alarmin in the immune system [44]. In macrophages, NPM1 negatively regulates cytokine and chemokine gene expression and their secretion [45]. We hypothesized that the NPM1 expression in tumor cells is modulated in response to microenvironmental stimuli.

We also demonstrated that NPM1 mRNA expression was inversely correlated with protein expression, which suggests that post-translational mechanisms may be 
involved in regulating expression of this protein. Previous studies demonstrated that NPM1 protein is modified by ubiquitylation [46-49], which may lead to its depletion despite the elevated mRNA transcription. Proteins make up the cellular machinery and play major roles in most biological processes. Thus, direct assessment of protein levels may often be more informative of the cellular state than analysis of mRNA levels [50]. Protein expression is subject to complex control and is only partly determined by accumulation and degradation of the corresponding mRNAs [51,52]; it is suggested that $20-60 \%$ of the variation in steady-state protein abundances is attributable to mRNA levels [53]. It has been speculated that transcriptional bursts, observed to increase variance in mRNA abundance, may be buffered by long protein half-lives [54].

In addition, NPM1 mRNA expression did not differ between tumors and non-neoplastic samples. Although approximately $45 \%$ of tumors presented reduced mRNA expression, about $27 \%$ of GC presented more than 1.5fold increased expression compared to matched nonneoplastic tissue. To our knowledge, only two previous studies evaluated NPM1 mRNA in gastric tumors by Northern blot. Tanaka et al. [21] reported that 2 of 3 tumors presented hybridization with NPM1 probe, which was not observed in any of the non-neoplastic samples. You et al. [22] demonstrated that 6 of 7 GC samples presented increased expression compared to non-neoplastic gastric tissue. However, the present study used RT-qPCR, the most sensitive method for detection and quantification of mRNA expression. Additionally, we evaluated a larger number of samples, which may better reflect the heterogeneity of gastric tumors.

Moreover, we observed that intestinal-type GC presented higher mRNA levels than diffuse-type GC, confirming that these two histological GC subtypes follow different genetic pathways and may be two distinct entities [55]. Although NPM1 mRNA seems to be higher in intestinal-type GC, this subtype showed relatively lower levels of NPM1 protein expression compared to the non-neoplastic samples, which reinforces the inverse correlation between NPM1 protein and mRNA expression.

\section{Conclusions}

We demonstrated that NPM1 down-regulation may have a role in gastric carcinogenesis, especially in intestinaltype GC and in tumors from patients with distant metastasis. However, NPM1 expression presented a large inter- and intra-tumor heterogeneity, which might complicate the development of diagnostic tests or treatments targeting the NPM1. On the other hand, NPM1 protein down-regulation may help in the selection of anticancer treatment strategies based on a better understanding of the pathways deregulated in GC.

\section{Abbreviations}

GC: Gastric cancer; NPM1: Nucleophosmin 1; CHAPS: 3-[(3-cholamidopropyl) dimethylammonio]-1-propanesulfonate; DTT: Dithiothreitol; PVDF: Polyvinylidene difluoride; ACTB: $\beta$-Actin; qPCR: quantitative PCR; RT-qPCR: Reverse transcription quantitative PCR; RQ: Relative quantification; SD: Standard deviation; ARF: Cyclin-dependent kinase inhibitor 2A (CDKNA2) alternate reading frame protein; MDM2: E3 ubiquitin-protein ligase.

\section{Competing interests}

The authors declare that they have no competing interests.

\section{Authors' contributions}

MFL, RC, RRB and MACS conceived and designed the experiments. MFL was involved in literature search, genetic and statistical analysis. TKFM, PDRC and MCM were involved in immunohistochemistry analysis. MFL and DQC were involved in data collection. SD was responsible for pathology analysis. PPA was responsible by samples collection. MFL wrote the first draft of the manuscript. All authors listed have contributed to all subsequent drafts, and have approved the final manuscript.

\section{Acknowledgements}

Supported by Conselho Nacional de Desenvolvimento Científico e Tecnológico (CNPq; RC, MACS and RRB) and Fundação de Amparo à Pesquisa do Estado de São Paulo (FAPESP; MFL, DQC and PDRC) as grants and fellowship awards. The authors are thankful to Sueli Nonogaki from Adolfo Lutz (São Paulo, SP, Brazil) for the technical support in the immunohistochemistry analyses.

\section{Author details}

${ }^{1}$ Genetics Division, Department of Morphology and Genetic, Federal University of São Paulo, R. Botucatu, 740, São Paulo, SP CEP 04023-900, Brazil. ${ }^{2}$ Department of Orthopedics and Traumatology, Federal University of São Paulo, São Paulo, SP 04038-031, Brazil. Experimental Oncology Laboratory, Department of Radiology, School of Medicine, University of São Paulo, São Paulo, SP 01246-903, Brazil. ${ }^{4}$ Center for Translational Oncology, São Paulo State Cancer Institute, São Paulo, SP 01246-000, Brazil. ${ }^{5}$ Research Center of Oncology, João de Barros Barreto University Hospital, Federal University of Pará, Belém, PA 60673-000, Brazil. ' Human Cytogenetics Laboratory, Institute of Biological Sciences, Federal University of Pará, Belém, PA 66073-000, Brazil.

Received: 5 March 2013 Accepted: 31 December 2013

Published: 10 January 2014

\section{References}

1. Jemal A, Bray F, Center MM, Ferlay J, Ward E, Forman D: Global cancer statistics. CA Cancer J Clin 2011, 61(2):69-90.

2. Leal MF, Chung J, Calcagno DQ, Assumpcao PP, Demachki S, da Silva ID, Chammas R, Burbano RR, de Arruda Cardoso Smith M: Differential proteomic analysis of noncardia gastric cancer from individuals of northern Brazil. PLoS One 2012, 7(7):e42255.

3. Grisendi S, Mecucci C, Falini B, Pandolfi PP: Nucleophosmin and cancer. Nat Rev Cancer 2006, 6(7):493-505.

4. Szebeni A, Olson MO: Nucleolar protein B23 has molecular chaperone activities. Protein Sci 1999, 8(4):905-912

5. Okuwaki $M$, Tsujimoto $M$, Nagata K: The RNA binding activity of a ribosome biogenesis factor, nucleophosmin/B23, is modulated by phosphorylation with a cell cycle-dependent kinase and by association with its subtype. Mol Biol Cell 2002, 13(6):2016-2030.

6. Okuda M: The role of nucleophosmin in centrosome duplication. Oncogene 2002, 21(40):6170-6174.

7. Tarapore P, Okuda M, Fukasawa K: A mammalian in vitro centriole duplication system: evidence for involvement of CDK2/cyclin E and nucleophosmin/B23 in centrosome duplication. Cell Cycle 2002, 1(1):75-81.

8. Grisendi S, Bernardi R, Rossi M, Cheng K, Khandker L, Manova K, Pandolfi PP: Role of nucleophosmin in embryonic development and tumorigenesis. Nature 2005, 437(7055):147-153.

9. Gimenez M, Souza VC, Izumi C, Barbieri MR, Chammas R, Oba-Shinjo SM, Uno M, Marie SK, Rosa JC: Proteomic analysis of low- to high-grade 
astrocytomas reveals an alteration of the expression level of raf kinase inhibitor protein and nucleophosmin. Proteomics 2010, 10(15):2812-2821.

10. Nozawa Y, Van Belzen N, Van der Made AC, Dinjens WN, Bosman FT: Expression of nucleophosmin/B23 in normal and neoplastic colorectal mucosa. J Pathol 1996, 178(1):48-52.

11. Yun JP, Miao J, Chen GG, Tian QH, Zhang CQ, Xiang J, Fu J, Lai PB: Increased expression of nucleophosmin/B23 in hepatocellular carcinoma and correlation with clinicopathological parameters. Br J Cancer 2007, 96(3):477-484

12. Tsui $\mathrm{KH}$, Cheng AJ, Chang PL, Pan TL, Yung BY: Association of nucleophosmin/B23 mRNA expression with clinical outcome in patients with bladder carcinoma. Urology 2004, 64(4):839-844.

13. Skaar TC, Prasad SC, Sharareh S, Lippman ME, Brunner N, Clarke R: Twodimensional gel electrophoresis analyses identify nucleophosmin as an estrogen regulated protein associated with acquired estrogenindependence in human breast cancer cells. J Steroid Biochem Mol Biol 1998, 67(5-6):391-402.

14. Shields LB, Gercel-Taylor C, Yashar CM, Wan TC, Katsanis WA, Spinnato JA, Taylor DD: Induction of immune responses to ovarian tumor antigens by multiparity. J Soc Gynecol Investig 1997, 4(6):298-304.

15. Subong EN, Shue MJ, Epstein Jl, Briggman JV, Chan PK, Partin AW: Monoclonal antibody to prostate cancer nuclear matrix protein (PRO:4-216) recognizes nucleophosmin/B23. Prostate 1999, 39(4):298-304.

16. Qian Z, Joslin JM, Tennant TR, Reshmi SC, Young DJ, Stoddart A, Larson RA, Le Beau MM: Cytogenetic and genetic pathways in therapy-related acute myeloid leukemia. Chem Biol Interact 2010, 184(1-2):50-57.

17. Naoe T, Suzuki T, Kiyoi H, Urano T: Nucleophosmin: a versatile molecule associated with hematological malignancies. Cancer Sci 2006, 97(10):963-969.

18. Mendes-da-Silva P, Moreira A, Duro-da-Costa J, Matias D, Monteiro C: Frequent loss of heterozygosity on chromosome 5 in non-small cell lung carcinoma. Mol Pathol 2000, 53(4):184-187.

19. Falini B, Martelli MP, Bolli N, Sportoletti P, Liso A, Tiacci E, Haferlach T: Acute myeloid leukemia with mutated nucleophosmin (NPM1): is it a distinct entity? Blood 2011, 117(4):1109-1120.

20. Zeller Kl, Haggerty TJ, Barrett JF, Guo Q, Wonsey DR, Dang CV: Characterization of nucleophosmin (B23) as a Myc target by scanning chromatin immunoprecipitation. J Biol Chem 2001, 276(51):48285-48291.

21. Tanaka M, Sasaki H, Kino I, Sugimura T, Terada M: Genes preferentially expressed in embryo stomach are predominantly expressed in gastric cancer. Cancer Res 1992, 52(12):3372-3377.

22. You BJ, Huang IJ, Liu WH, Hung YB, Chang JH, Yung BY: Decrease in nucleophosmin/B23 mRNA and telomerase activity during indomethacin-induced apoptosis of gastric KATO-III cancer cells. Naunyn Schmiedebergs Arch Pharmacol 1999, 360(6):683-690.

23. Lauren $P$ : The two histological main types of gastric carcinoma: diffuse and so-called intestinal-type carcinoma. an attempt at a histo-clinical classification. Acta Pathol Microbiol Scand 1965, 64:31-49.

24. Sobin LH, Gopodarowicz MK, Wittekind C: TNM Classification of Malignant Tumors. 7th edition. Oxford: Wiley-Blackwell; 2009.

25. Clayton CL, Kleanthous H, Coates PJ, Morgan DD, Tabaqchali S: Sensitive detection of Helicobacter pylori by using polymerase chain reaction. J Clin Microbiol 1992, 30(1):192-200.

26. Lobo Gatti L, Agostinho Jn F, De Labio R, Balbo Piason F, Carlos Da Silva $L$, Fagundez De Queiroz V, Peres CA, Barbieri D, De Arruda Cardoso Smith M, Marques Payao SL: Helicobacter pylori and cagA and vacA gene status in children from Brazil with chronic gastritis. Clin Exp Med 2003, 3(3):166-172.

27. Pfaffl MW: A new mathematical model for relative quantification in real-time RT-PCR. Nucleic Acids Res 2001, 29(9):e45

28. Kamijo T, Zindy F, Roussel MF, Quelle DE, Downing JR, Ashmun RA, Grosveld G, Sherr CJ: Tumor suppression at the mouse INK4a locus mediated by the alternative reading frame product p19ARF. Cell 1997, 91(5):649-659.

29. Kuo ML, den Besten W, Bertwistle D, Roussel MF, Sherr CJ: N-terminal polyubiquitination and degradation of the Arf tumor suppressor. Genes Dev 2004, 18(15):1862-1874.

30. Karhemo PR, Rivinoja A, Lundin J, Hyvonen M, Chernenko A, Lammi J, Sihto H, Lundin M, Heikkila P, Joensuu $H$, et al: An extensive tumor array analysis supports tumor suppressive role for nucleophosmin in breast cancer. Am J Pathol 2011, 179(2):1004-1014.
31. Liu Y, Zhang F, Zhang XF, Qi LS, Yang L, Guo H, Zhang N: Expression of nucleophosmin/NPM1 correlates with migration and invasiveness of colon cancer cells. J Biomed Sci 2012, 19:53

32. Bonetti P, Davoli T, Sironi C, Amati B, Pelicci PG, Colombo E: Nucleophosmin and its AML-associated mutant regulate c-Myc turnover through Fbw7 gamma. J Cell Biol 2008, 182(1):19-26.

33. Calcagno DQ, Leal MF, Assumpcao PP, Smith MA, Burbano RR: MYC and gastric adenocarcinoma carcinogenesis. World J Gastroenterol 2008, 14(39):5962-5968.

34. Leal MF, Calcagno DQ, Khayat AS, Silva TC, Muniz JA, Assumpcao PP, de Arruda Cardoso Smith M, Burbano RR: hTERT and TP53 deregulation in intestinal-type gastric carcinogenesis in non-human primates. Clin Exp Med 2013, 13(3):221-224

35. Assumpcao PP, Ishak G, Chen ES, Takeno SS, Leal MF, Guimaraes AC, Calcagno DQ, Khayat AS, Demachki S, Smith Mde A, et al: Numerical aberrations of chromosome 8 detected by conventional cytogenetics and fluorescence in situ hybridization in individuals from northern Brazil with gastric adenocarcinoma. Cancer Genet Cytogenet 2006, 169(1):45-49.

36. Burbano RR, Assumpcao PP, Leal MF, Calcagno DQ, Guimaraes AC, Khayat AS, Takeno SS, Chen ES, De Arruda Cardoso SM: C-MYC locus amplification as metastasis predictor in intestinal-type gastric adenocarcinomas: $\mathrm{CGH}$ study in Brazil. Anticancer Res 2006, 26(4B):2909-2914.

37. Calcagno DQ, Guimaraes AC, Leal MF, Seabra AD, Khayat AS, Pontes TB, Assumpcao PP, De Arruda Cardoso SM, Burbano RR: MYC insertions in diffuse-type gastric adenocarcinoma. Anticancer Res 2009, 29(7):2479-2483.

38. Calcagno DQ, Leal MF, Demachki S, Araujo MT, Freitas FW, Oliveira e Souza D, Assumpcao PP, Ishak G, de Arruda Cardoso Smith M, Burbano RR: MYC in gastric carcinoma and intestinal metaplasia of young adults. Cancer Genet Cytogenet 2010, 202(1):63-66.

39. Calcagno DQ, Leal MF, Seabra AD, Khayat AS, Chen ES, Demachki S, Assumpcao PP, Faria MH, Rabenhorst SH, Ferreira MV, et al: Interrelationship between chromosome 8 aneuploidy, C-MYC amplification and increased expression in individuals from northern Brazil with gastric adenocarcinoma. World J Gastroenterol 2006, 12(38):6207-6211.

40. Calcagno DQ, Leal MF, Taken SS, Assumpcao PP, Demachki S, Smith Mde A, Burbano RR: Aneuploidy of chromosome 8 and C-MYC amplification in individuals from northern Brazil with gastric adenocarcinoma. Anticancer Res 2005, 25(6B):4069-4074.

41. Costa Raiol LC, Figueira Silva EC, Mendes Da Fonseca D, Leal MF, Guimaraes AC, Calcagno DQ, Khayat AS, Assumpcao PP, De Arruda Cardoso Smith M, Burbano RR: Interrelationship between MYC gene numerical aberrations and protein expression in individuals from northern Brazil with early gastric adenocarcinoma. Cancer Genet Cytogenet 2008, 181(1):31-35.

42. Rosal-Texeira C, Leal MF, Calcagno DQ, Sozinho EKC, Borges BN, Montenegro RC, Santos AKR, Santos SEB, Ribeiro HF, Assumpção PP, et al: MYC deregulation in gastric cancer and its clinicopathological implications. PLoS One 2013. in press.

43. Lindstrom MS: NPM1/B23: a multifunctional chaperone in ribosome biogenesis and chromatin remodeling. Biochem Res Int 2011, 2011:195209.

44. Nawa Y, Kawahara K, Tancharoen S, Meng X, Sameshima H, Ito T, Masuda Y, Imaizumi H, Hashiguchi T, Maruyama I: Nucleophosmin may act as an alarmin: implications for severe sepsis. J Leukoc Biol 2009, 86(3):645-653.

45. Guery L, Benikhlef N, Gautier T, Paul C, Jego G, Dufour E, Jacquel A, Cally R, Manoury B, Vanden Berghe T, et al: Fine-tuning nucleophosmin in macrophage differentiation and activation. Blood 2011, 118(17):4694-4704.

46. Enomoto T, Lindstrom MS, Jin A, Ke H, Zhang Y: Essential role of the B23/ NPM core domain in regulating ARF binding and B23 stability. J Biol Chem 2006, 281(27):18463-18472.

47. Itahana K, Bhat KP, Jin A, Itahana Y, Hawke D, Kobayashi R, Zhang Y: Tumor suppressor ARF degrades B23, a nucleolar protein involved in ribosome biogenesis and cell proliferation. Mol Cell 2003, 12(5):1151-1164.

48. Endo A, Matsumoto M, Inada T, Yamamoto A, Nakayama Kl, Kitamura N, Komada M: Nucleolar structure and function are regulated by the deubiquitylating enzyme USP36. J Cell Sci 2009, 122(Pt 5):678-686.

49. Sato K, Hayami R, Wu W, Nishikawa T, Nishikawa H, Okuda Y, Ogata H, Fukuda M, Ohta T: Nucleophosmin/B23 is a candidate substrate for the BRCA1-BARD1 ubiquitin ligase. J Biol Chem 2004, 279(30):30919-30922.

50. Laurent JM, Vogel C, Kwon T, Craig SA, Boutz DR, Huse HK, Nozue K, Walia $\mathrm{H}$, Whiteley $\mathrm{M}$, Ronald PC, et al: Protein abundances are more conserved than mRNA abundances across diverse taxa. Proteomics 2010, 10(23):4209-4212 
51. Lu P, Vogel C, Wang R, Yao X, Marcotte EM: Absolute protein expression profiling estimates the relative contributions of transcriptional and translational regulation. Nat Biotechnol 2007, 25(1):117-124.

52. Anderson L, Seilhamer J: A comparison of selected mRNA and protein abundances in human liver. Electrophoresis 1997, 18(3-4):533-537.

53. de Sousa AR, Penalva LO, Marcotte EM, Vogel C: Global signatures of protein and mRNA expression levels. Mol Biosyst 2009, 5(12):1512-1526.

54. Raj A, Peskin CS, Tranchina D, Vargas DY, Tyagi S: Stochastic mRNA synthesis in mammalian cells. PLOS Biol 2006, 4(10):e309.

55. Tahara E: Genetic pathways of two types of gastric cancer. IARC Sci Publ 2004, 157:327-349.

doi:10.1186/1471-230X-14-9

Cite this article as: Leal et al:: Deregulated expression of Nucleophosmin

1 in gastric cancer and its clinicopathological implications. BMC

Gastroenterology 2014 14:9.

\section{Submit your next manuscript to BioMed Central and take full advantage of:}

- Convenient online submission

- Thorough peer review

- No space constraints or color figure charges

- Immediate publication on acceptance

- Inclusion in PubMed, CAS, Scopus and Google Scholar

- Research which is freely available for redistribution 